\title{
Pleural Fluid Infranatant
}

National Cancer Institute

\section{Source}

National Cancer Institute. Pleural Fluid Infranatant. NCI Thesaurus. Code C106558.

The liquid, solid or semi-solid lying below a liquid residue, which is separated by

crystallization, precipitation or centrifugation of a pleural fluid sample. 